\title{
Change in tartrate-resistant acid phosphatase isoform 5 b levels, a marker of bone metabolism, in patients with chronic hepatitis B treated with tenofovir alafenamide
}

\author{
TAKUMA OKAMURA ${ }^{1,2}$, TATSUKI ICHIKAWA ${ }^{1-3}$, HISAMITSU MIYAAKI $^{4}$, SATOSHI MIUMA $^{4}$, \\ YASUHIDE MOTOYOSHI ${ }^{1}$, MIO YAMASHIMA ${ }^{1}$, SHINOBU YAMAMICHI ${ }^{1}$, MAKIKO KOIKE ${ }^{3}$, \\ YUSUKE NAKANO $^{3}$, TETSUROU HONDA ${ }^{1}$, HIROYUKI YAJIMA ${ }^{1}$, OSAMU MIYAZAKI ${ }^{1}$, \\ YASUTAKA KURIBAYASHI ${ }^{1}$, TOMONARI IKEDA ${ }^{1}$, NAOTA TAURA ${ }^{4}$ and KAZUHIKO NAKAO ${ }^{4}$ \\ ${ }^{1}$ Department of Gastroenterology, Nagasaki Harbor Medical Center, Nagasaki 850-8555; \\ ${ }^{2}$ Department of Comprehensive Community Care Systems, Graduate School of Biomedical Sciences, \\ Nagasaki University, Nagasaki 852-8501; ${ }^{3}$ Innovation and Translational Research Center, Nagasaki \\ Harbor Medical Center, Nagasaki 850-8555; ${ }^{4}$ Department of Gastroenterology and Hepatology, \\ Graduate School of Biomedical Sciences, Nagasaki University, Nagasaki 852-8501, Japan
}

Received August 11, 2021; Accepted November 1, 2021

DOI: $10.3892 / \mathrm{br} .2021 .1489$

\begin{abstract}
Hepatitis B virus (HBV) infection is associated with the risk of osteoporosis and bone mineral density (BMD) loss. Tenofovir alafenamide (TAF) is associated with a slightly lower degree of BMD loss compared with tenofovir disoproxil, without loss of the excellent anti-HBV effects. The aim of the present study was to verify the effect of bone metabolism in patients with HBV treated with TAF. A total of 87 patients were treated with TAF. Of these, 32 patients were treatment naïve, and 55 patients were treated with entecavir (ETV) for at least 1 year, after which ETV was switched to TAF. At the start of TAF and after 1 year, BMD in the lumbar and neck of the femur, tartrate-resistant acid phosphatase isoform $5 \mathrm{~b}$ (TRACP-5b) levels as a marker of bone metabolism and serum inorganic phosphorus $(\mathrm{P})$ were compared to estimate bone metabolism. Serum creatinine $(\mathrm{Cr})$, cystatin $\mathrm{C}$, urine protein and $\beta 2$ microglobulin levels were evaluated to estimate kidney function. Treatment with TAF for 1 year decreased TRACP-5b levels, particularly in patients with bone disease, except for a minimal significant change (MSC; decrease of $12.4 \%$ ) in TRACP-5b levels. The change in rate of TRACP-5b levels were positively associated with changes in $\mathrm{P}, \mathrm{Cr}$-estimated glomerular filtration rate and TRACP-5b levels at the start of TAF. Logistic regression analysis showed that increased BMD
\end{abstract}

Correspondence to: Dr Tatsuki Ichikawa, Department of Gastroenterology, Nagasaki Harbor Medical Center, 6-39 Shinchi, Nagasaki 850-8555, Japan

E-mail: ichikawa@nagasaki-u.ac.jp

Key words: bone mineral density, hepatitis $\mathrm{B}$ virus, tenofovir alafenamide, tartrate-resistant acid phosphatase isoform $5 \mathrm{~b}$ in the lumbar region contributed to the switch from ETV to TAF. TAF induced a decrease in TRACP-5b levels in patients with HBV. Bone disease was a contributing factor for MSC. Since TRACP-5b can be used as a marker of bone metabolism and fractures, TAF may exhibit potential in preventing fractures in patients with $\mathrm{HBV}$.

\section{Introduction}

Hepatitis B virus (HBV) infection causes cirrhosis and hepatocellular carcinoma $(1,2)$; de novo $\mathrm{HBV}$ infection also causes acute liver failure (2). Treatment for HBV infection focuses on improving survival and quality of life by preventing disease progression (3). Long-term administration of a potent nucleoside/nucleotide analog (NA) with a high barrier to resistance is the treatment of choice regardless of the severity of liver disease, and the preferred regimens are entecavir (ETV), tenofovir disoproxil (TDF) and tenofovir alafenamide (TAF) (3). In cases of long-term administration of NA, patients are at an increased risk of renal disease and should undergo periodic renal monitoring, including at least estimated glomerular filtration rate (eGFR) and serum phosphate level (3). Chronic HBV infection is associated with kidney damage (4), and follow-up of renal function in patients with $\mathrm{HBV}$ is important during treatment.

Additionally, hepatic osteodystrophy (HOD) is common in chronic liver diseases, including viral hepatitis (5-7). HOD includes osteoporosis and osteomalacia, which are caused by hormonal abnormality-induced advanced liver failure complicated with abnormal serum calcium and phosphate (5-7). HBV infection is associated with the risk of osteoporosis and bone mineral density (BMD) loss $(8,9)$. The bone metabolic marker, tartrate-resistant acid phosphatase isoform 5b (TRACP-5b), is an activation marker of osteoclasts, and is elevated in patients with HOD associated with chronic liver disease (6). TR ACP-5b 
levels from baseline to 3 months after treatment may predict the efficacy of bone therapy after 12 months (10). Therefore, measurements of BMD and bone metabolic markers are useful in the diagnosis and management of osteoporosis (11).

TAF is associated with a slightly lower degree of BMD loss and creatinine $(\mathrm{Cr})$ elevation compared with TDF, without loss of the excellent anti-viral effects (12-14). Patients on TDF that are at a risk of development of or have already developed underlying renal or bone disease should be considered for a switch to ETV or TAF (3). However, switching from ETV to TAF is contested. When ETV was switched to TAF, serum $\mathrm{Cr}$ (15) or renal tubular function (16) improved, hepatitis B surface antigen (HBsAg) decreased, however no-change in BMD and renal function were observed (17). ETV is administered orally once daily under fasting conditions, and TAF is administered orally once daily. Switching from ETV to TAF can be a useful approach for improving medication adherence and satisfaction $(18,19)$.

Based on favorable adherence, TAF is being chosen for the treatment naïve patients with $\mathrm{HBV}$ in our hospital, and patients have been encouraged to switch from ETV to TAF since 2017. In this study, the influence of TAF treatment on bone metabolism and kidney function for 1 year of TAF treatment was evaluated.

\section{Patients and methods}

Patients. A total of 87 patients with HBV infection were admitted to the Nagasaki Harbor Medical Center between April 2017 and February 2020. Of these, 32 patients (median age, 58.96; range, 36-86; female/male, 14/18) were naïve to treatment with TAF (Vemlidy, Gilead Sciences) (Naïve group), and 55 patients (median age, 59.89; range, 35-82; female/male, 15/40) were treated with ETV (Baraclude, Bristol-Myers Sqibb) for at least 1 year, and switched to TAF (Switch group). The reason for switching was to ensure drug compliance, adjusted for lifestyle. ETV was administered orally at a dose of $0.5 \mathrm{mg}$ once daily under fasting conditions. TAF was administered orally at a dose of $25 \mathrm{mg}$ once daily. No patients were treated for osteoporosis before TAF initiation. The medical records of the 87 patients were compared at the start of TAF and after 1 year. The prevention group was treated with TAF for asymptomatic HBV using immunosuppressants and/or anticancer drugs. The bone disease-positive group was defined as follows: Chronic steroid use or use of other medications that worsen bone density and/or history of fragility fracture and/or osteoporosis.

The medical records of the 87 patients were retrospectively reviewed. Informed consent was obtained from each patient included in the study, and the patients were guaranteed the right to leave the study if they desired. The study protocol conformed to the ethical guidelines of the 1975 Declaration of Helsinki (20) and was approved by the Human Research Ethics Committee of the Nagasaki Harbor Medical Center (approval no. H30-031).

Laboratory measurements. Laboratory data and anthropometric measurements were obtained for each subject every 4-12 weeks during treatment, and BMD and urinalysis were examined every 12 months. The body mass index of each patient was calculated by dividing their weight in $\mathrm{kg}$ by the square of their height in meters. Laboratory examinations included platelet count, $\mathrm{Cr}$, cystatin $\mathrm{C}$ (CysC), albumin, total bilirubin, alanine aminotransferase (ALT), calcium (Ca), inorganic phosphorus (P), $\alpha$-fetoprotein, protein induced by vitamin $\mathrm{K}$ absence-II (PIVKA-II), Mac-2 binding protein glycan isomer (M2BPGi), total type I procollagen $\mathrm{N}$-propeptide (P1NP), and tartrate-resistant acid phosphatase $5 b$ (TRACP-5b). HBsAg, HBeAg, HBe antibody (HBeAb), HB core-related Ag (HBcrAg) and HBV-DNA were evaluated at the start of TAF administration and 1 year later. Urinalysis was performed using the $\beta 2$-microglobulin-to-creatinine $\beta 2 \mathrm{MG} / \mathrm{Cr}$ ratio and total protein-to-creatinine protein/Cr ratio. Radiological findings in the present study.

Osteoporosis, osteopenia and normal BMD were diagnosed according to the World Health Organization criteria (osteoporosis, T-score $\leq$-2.5; osteopenia, T-score between -2.5 and -1; normal BMD: T-score $>-1$ ) (21). Bone mineral density was measured at the lumbar spine (mean, L2-L4) and femoral neck using dual-energy X-ray absorptiometry (DEXA).

Cr- and CysC-based estimated GFRs (eGFRs) $\left(\mathrm{ml} / \mathrm{min} / 1.73 \mathrm{~m}^{2}\right)$ in women and men were calculated using the equations provided by the Japanese Society of Nephrology for Japanese patients (22). The sarcopenia index (SI) was calculated as follows: $\mathrm{Cr} / \mathrm{CysC}$ x100 (23). The calculated body muscle mass (CBMM) was calculated as follows: (body weight in $\mathrm{kg} \mathrm{x} \mathrm{Cr}$ /[ $[\mathrm{K}$ x body weight in $\mathrm{kg}$ x CysC) $+\mathrm{Cr}]$, where $\mathrm{K}=0.00675$ for men and 0.01006 for women (24).

Statistical analysis. Data were analyzed using StatFlex version 6.0 (Artech Co., Ltd.) and are presented as the mean \pm standard deviation. Laboratory result variables were compared using a Wilcoxon test for differences between paired groups, a Mann-Whitney tests comparison for unpaired two groups, and a $\chi^{2}$ test for comparison between discrete variables. A standardized partial regression coefficient $\beta$ was employed. Univariate and multivariate analyses were performed using a logistic regression analysis. Correlations were evaluated using Pearson's correlation coefficient $(\mathrm{R}) . \mathrm{P}<0.05$ was considered to indicate a statistically significant difference.

\section{Results}

The clinical characteristics of the patients at the start of TAF and after 1 year, are described in Table I. It was observed that male patients were dominant and 51 patients were $\geq 60$ years of age. The prevention group included patients with asymptomatic HBV infection treated with TAF as part of an anticancer or immunosuppressive therapy. During the 1-year observation period, HBsAg levels were not significantly altered, but $\mathrm{HBcrAg}$ and HBV-DNA levels significantly decreased. Albumin levels increased and M2BPGi levels decreased. Regarding renal function, $\mathrm{Cr}$ levels were increased, Cr-based eGFR decreased and urine protein $/ \mathrm{Cr}$ ratio increased. CysC, CysC eGFR, Ca, $\mathrm{P}$ and urine $\beta 2 \mathrm{MG} / \mathrm{Cr}$ ratios were not significantly changed. In bone metabolism, lumbar BMD did not change, but the BMD of the neck of femur decreased. However, TRACP-5b levels significantly improved. P1NP was not measured after 1 year.

A focus was placed on the change in TRACP-5b associated with TAF. The change in TRACP-5b levels were compared 
Table I. Clinical characteristics at start of treatment and after 1 year.

\begin{tabular}{|c|c|c|c|}
\hline Factor & At start & After 1 year & P-value \\
\hline Female/male, $\mathrm{n}$ & $29 / 58$ & $29 / 58$ & \\
\hline Age, years & $59.55(12)$ & & - \\
\hline Age bracket, $n$ & & & - \\
\hline$\geq 60$ years & 51 & & \\
\hline$<60$ years & 37 & & \\
\hline Body weight, kg & $61.83(12.1)$ & $61.91(12.18)$ & 0.5899 \\
\hline Body mass index, $\mathrm{kg} / \mathrm{m}^{2}$ & $23.07(3.64)$ & & \\
\hline \multicolumn{4}{|l|}{ Groups, $\mathrm{n}$} \\
\hline Naïve & 32 & & \\
\hline Switch & 55 & & \\
\hline Prevention & 20 & & \\
\hline HBsAg IU/ml & $3,134(9,744)$ & $2,115(3,697)$ & 0.0005 \\
\hline HBcrAg Log U/ml & $3.457(1.612)$ & $3.11(1.485)$ & $<0.0001^{\mathrm{c}}$ \\
\hline HBcrAg positive, $n$ & 45 & 36 & $<0.001^{\mathrm{c}}$ \\
\hline HBeAg C.O.I. & $97.756(376)$ & $55.628(271)$ & $0.0352^{\mathrm{a}}$ \\
\hline HBeAg positive, $n$ & 13 & 13 & 0.999 \\
\hline $\mathrm{HBe} \mathrm{Ab} \%$ inhibition & $74.41(34.12)$ & $72.84(32.5)$ & 0.2149 \\
\hline HBV-DNA log IU/ml & $1.80(2.522)$ & $0.251(0.559)$ & $<0.0001^{\mathrm{d}}$ \\
\hline HBV-DNA positive, $n$ & 41 & 17 & $<0.0001^{\mathrm{d}}$ \\
\hline AST U/1 & $68.92(227.13)$ & $26.73(14.85)$ & $0.019^{\mathrm{a}}$ \\
\hline ALT U/1 & $79.91(310.1)$ & $24.97(21.05)$ & $0.0241^{\mathrm{a}}$ \\
\hline Platelet $\times 10^{4} / \mu 1$ & $17.86(7.164)$ & $18.64(17.49)$ & 0.342 \\
\hline Albumin g/dl & $4.098(0.578)$ & $4.226(0.456)$ & $0.0053^{\mathrm{b}}$ \\
\hline Total bilirubin mg/dl & $0.921(0.985)$ & $0.907(0.577)$ & $0.0198^{\mathrm{a}}$ \\
\hline M2BPGi C.O.I & $1.436(2.05)$ & $1.058(1.37)$ & $0.0014^{\mathrm{b}}$ \\
\hline $\mathrm{Cr} \mathrm{mg} / \mathrm{d}$ & $0.825(0.248)$ & $0.857(0.219)$ & $0.0007^{\mathrm{c}}$ \\
\hline Cr-eGFR ml/min $/ 1.73 \mathrm{~m}^{2}$ & $72.945(19.006)$ & $68.51(16.91)$ & $<0.0001$ \\
\hline Cys C mg/l & $1.103(0.345)$ & $1.098(0.328)$ & 0.6944 \\
\hline Cys C-eGFR ml/min $/ 1.73 \mathrm{~m}^{2}$ & $70.74(22.66)$ & $70.36(22.49)$ & 0.6253 \\
\hline Sarcopenia index ${ }^{\mathrm{e}}$ & $77.21(18.4)$ & $80.69(817.82)$ & $0.0424^{\mathrm{a}}$ \\
\hline $\mathrm{Ca} \mathrm{mg/dl}$ & $9.074(0.493)$ & $9.138(0.486)$ & 0.2563 \\
\hline $\mathrm{P} \mathrm{mg/dl}$ & $3.127(0.502)$ & $3.193(0.522)$ & 0.4027 \\
\hline Urine protein/Cr g/g & $0.147(0.383)$ & $0.199(0.536)$ & $0.0205^{\mathrm{a}}$ \\
\hline Urine $\mathrm{b} 2 \mathrm{MG} / \mathrm{Cr} \mu \mathrm{g} / \mathrm{mg}$ & $4.499(19.301)$ & $7.845(32.666)$ & 0.9357 \\
\hline Lumbar BMD g/cm ${ }^{2}$ & $0.906(0.206)$ & $0.907(0.2)$ & 0.2041 \\
\hline Lumbar t-score & $-1.09(1.697)$ & $-1.091(1.668)$ & 0.4505 \\
\hline Lumbar young adult mean & $87.62(19.614)$ & $87.427(18.833)$ & 0.7057 \\
\hline Lumbar osteoporosis, $\mathrm{n}$ & 19 & 15 & 0.3409 \\
\hline Neck of femur BMD g/cm² & $0.66(0.142)$ & $0.636(0.132)$ & $<0.0001^{\mathrm{d}}$ \\
\hline Neck of femur t-score & $-1.504(1.111)$ & $-1.699(1.026)$ & $0.0001^{\mathrm{d}}$ \\
\hline Neck of femur young adult mean & $78.785(15.523)$ & $75.813(14.659)$ & $<0.0001^{\mathrm{d}}$ \\
\hline Neck of femur Osteoporosis, $\mathrm{n}$ & 13 & 21 & 0.0625 \\
\hline TRACP-5b mU/dl & $417.7(207)$ & $356.5(142.3)$ & $0.0039^{\mathrm{b}}$ \\
\hline TRACP-5b High, n & 18 & 13 & 0.1714 \\
\hline P1NP ng/ml & $55.05(28.25)$ & & \\
\hline P1NP High & 9 & 0 & \\
\hline
\end{tabular}

with clinical factors (Table II). TRACP-5b at start in male patients, patients who were $\mathrm{HBeAg}$-positive, $\mathrm{HBcrAg}$-positive, HBV-DNA-negative, switch, treatment, high albumin $(\geq 4 \mathrm{~g} / \mathrm{dl})$, high platelet count $\left(\geq 15 \times 10^{4} / \mu \mathrm{l}\right)$ and low body mass index $(<25)$ were lower than after 1 year. In conforming with the EASL guidelines (4), old age ( $\geq 60$ years), bone disease [chronic steroid use or use of other medications that worsen bone density and/or history of fragility fracture and/or 
Table I. Continued.

\begin{tabular}{llcr}
\hline Factor & \multicolumn{1}{c}{ At start } & After 1 year & P-value \\
\hline$\alpha$-fetoprotein ng/ml & $10.64(25)$ & $4.93(4.5)$ & 0.6469 \\
PIVKA-II mAU/ml & $38.33(114.3)$ & $38.46(106.5)$ & 0.4463 \\
\hline
\end{tabular}

${ }^{\mathrm{a}} \mathrm{P} \leq 0.05,{ }^{\mathrm{b}} \mathrm{P} \leq 0.01,{ }^{\mathrm{c}} \mathrm{P} \leq 0.001,{ }^{\mathrm{d}} \mathrm{P} \leq 0.0001 .{ }^{\mathrm{e}} \mathrm{Data}$ are presented as the mean \pm standard deviation. Co.O.I., cut off index. The sensitivity of HBsAg is $0.005 \mathrm{IU} / \mathrm{ml}$. The sensitivity of HBcrAg is $2.9 \mathrm{log} \mathrm{U} / \mathrm{ml}$. The sensitivity of HBeAg is 1.0 cut off index. Positive HBeAb was $<60 \%$ inhibition. The HBV-DNA detection level ranged from 1-9.1 log IU/ml. The normal range of AST is 10-40 U/1. The normal range of ALT is 5-45 U/1. The normal range of platelet counts is $14.0-37.9 \times 10^{4} / \mu 1$. The normal range of albumin is 3.7-5.5 $\mathrm{g} / \mathrm{dl}$. The normal range of total bilirubin is $0.3-1.2 \mathrm{mg} / \mathrm{dl}$. Unit of M2BPGi is C.O.I. The normal range of $\mathrm{Cr}$ is $0.65-1.09$ (male) and $0.46-0.82$ (female) $\mathrm{mg} / \mathrm{dl}$. The Cr-based eGFR is $\mathrm{ml} / \mathrm{min} / 1.73 \mathrm{~m}^{2}$. Normal range of CysC is $0.58-0.87$ (male) and 0.47-0.82 (female) $\mathrm{mg} / \mathrm{l}$. CysC-eGFR is $\mathrm{ml} / \mathrm{min} / 1.73 \mathrm{~m}{ }^{2}$. The sarcopenia index was calculated as follows: serum $\mathrm{Cr} / \mathrm{CysC} \mathrm{x} 100$. The normal range of calcium $(\mathrm{Ca})$ is $8.5-10.2 \mathrm{mg} / \mathrm{dl}$. The normal range of $\mathrm{P}$ is $2.4-4.3 \mathrm{mg} / \mathrm{dl}$. The urine protein $/ \mathrm{Cr}$ ratio was $\mathrm{g} / \mathrm{g}$. Urine $\beta 2 \mathrm{MG} / \mathrm{Cr}$ was $\mu \mathrm{g} / \mathrm{mg}$. Lumbar bone mineral density is the mean of the lumbar spine $2-4$ and is measured in $\mathrm{g} / \mathrm{cm}^{2}$. The young adult mean (lumber spine, 20-44 years of age) is $1.19 \mathrm{~g} / \mathrm{cm}^{2}$ in men and $1.12 \mathrm{~g} / \mathrm{cm}^{2}$ in women. The YAM (femur neck) was $0.95 \mathrm{~g} / \mathrm{cm}^{2}$ in men and $0.90 \mathrm{~g} / \mathrm{cm}^{2}$ in female. A T-score $\leq-2.5$ indicates osteoporosis. The normal range of TRACP-5b is $170-590$ in males and 120-420 in females (mU/dl). The TRACP-5b High group was over the upper limits. Normal range of total P1NP is 18.1-74.1 in male, 16.8-70.1 in premenopausal female and 26.4-98.2 in postmenopausal (ng/ml). The P1NP High group was over the upper limits. The normal range of $\alpha$-fetoprotein was under $10 \mathrm{ng} / \mathrm{ml}$. The normal range of protein induced by PIVKA-II is $<40 \mathrm{mAU} / \mathrm{ml}$.

osteoporosis) and renal alteration (eGFR $<60 \mathrm{ml} / \mathrm{min} / 1.73 \mathrm{~m}^{2}$ and/or moderate dipstick proteinuria and/or low $\mathrm{P}(<2.5 \mathrm{mg} / \mathrm{dl})$ and/or hemodialysis] were selected for the disease group. Old age ( $\geq 60$ years) and bone disease significantly decreased TRAC-5b levels. Next, whether these factors contributed to the decrease in TRCAP-5b levels with TAF use was assessed. Since bone metabolic markers have various circadian variations, MSCs were set for each marker. The MSC of TRACP-5b showed over a $12.4 \%$ of change rate [(pre-treatment-after treatment)/pretreatment $\mathrm{x} 100]$. Therefore, the contribution of TRACP-5b to MSCs (32 cases) was evaluated. Univariate logistic regression analysis revealed that bone disease was the only contributing factor for MSCs. The bone disease group had lower BMD in the lumbar and neck of the femur at start and after 1 year compared with the control group. A high tendency of TRACP-5b levels at the start was observed, however there was no difference in TRACP-5b levels after 1 year (Fig. 1A-C).

Next, the relationship between TRACP-5b rate change and clinical factors at the start of TAF were evaluated (Table III). Cr-eGFR, P, P1NP and TR ACP-5b were positively correlated with the TRACP-5b rate of change. Amongst these factors, Cr-eGFR and TRACP-5b were related to the TRCAP-5b rate of change in the multi-regression model. The change in these factors (at the start of TAF and after 1 year) was also evaluated in relation to the TRACP-5b rate of change (Table III). The change in $\mathrm{P}$ was only related to the TRACP-5b rate of change.

Changes in lumbar BMD were evaluated based on clinical factors (Table IV). The clinical factors were the same as in Table II. The Switch group exhibited increased BMD only in the lumbar region, but the control group (naïve group) did not exhibit any significant changes. Increases in BMD were significant between the start and after 1 year, [ 44 cases exhibited increased BMD after 1 year compared with at the start]. Logistic univariate analysis showed that the switch was a contributing factor for the increased BMD in the lumbar spine. The Switch group did not exhibit a difference in BMD of the lumbar and neck of the femur and TRACP-5b at the start and after 1 year compared to the control (Fig. 1D-F). BMD in the lumbar region after 1 year in the switch group increased more than at the start (Fig. 1D), and TRACP-5b after 1 year after switching also decreased more than at the start (Fig. 1F).

Similarly, the change in BMD in the neck of the femur was also evaluated based on several clinical factors (Table V). Male sex, prevention group, low albumin levels and a low BMI did not decrease BMD in the neck of the femur after 1 year. Changes in BMD in the femoral neck were evaluated. There were 18 cases of increased BMD (at start-after 1 year). Logistic univariate analysis revealed that female sex was the only factor for increased BMD in the neck of the femur. The number of patients with increased BMD (18 cases) in the femoral neck was less than that in the lumbar region (44 cases, $\mathrm{P}=0.0001$ ) and MSCs in TR ACP-5b (32 cases, $\mathrm{P}=0.0289)$. BMD in the femoral neck was lower in females than in males at the start and after 1 year; however there was no difference between the start and after 1 year in females (Fig. 1H). BMD in the lumbar spine and TRACP-5b also showed no difference between the start and after 1 year in females (Fig. 1G and I).

\section{Discussion}

Treatment with TAF for 1 year decreased TRACP-5b levels, especially in patients with bone disease, excluding the MSC of TRACP-5b. The rate of change of TRACP-5b was associated with changes in P, Cr-eGFR and TRACP-5b levels at the start of TAF. Increased BMD in the lumbar region contributed to the switch from ETV to TAF. Increased BMD in the neck of the femur was present in female patients.

TRACP-5b at the start of TAF was related to the rate of change of TRACP-5b. HBV-infected patients exhibited hyperosteoclast function before TAF treatment. Carbon tetrachloride induced liver damage may have increased the levels of TRACP-5b (25), and HOD has been reported to increase TRACP-5b levels in patients with chronic liver 
Table II. Change in TRACP-5b levels and contributing factors in the MSC of TRACP-5b.

Comparison of TRACP-5b between at start and after 1 year

Logistical analysis for MSC of TRACP-5b

\begin{tabular}{|c|c|c|c|c|c|c|}
\hline \multirow[b]{2}{*}{ Group (n) } & \multicolumn{3}{|c|}{ and after 1 year } & \multirow{2}{*}{$\begin{array}{l}\text { Odds } \\
\text { ratio }\end{array}$} & \multirow[b]{2}{*}{$\begin{array}{l}95 \% \text { Confidence } \\
\text { interval }\end{array}$} & \multirow[b]{2}{*}{$\mathrm{P}$-value } \\
\hline & At start $\mathrm{d}^{\mathrm{d}}$ & After 1 year $^{\mathrm{d}}$ & P-value & & & \\
\hline Female (29) & $431(216.6)$ & $381.68(143.3)$ & 0.374 & & & \\
\hline Male (58) & $410.1(203.2)$ & $343.9(141.2)$ & $0.0016^{\mathrm{b}}$ & 1.082 & $0.422-2.773$ & 0.8699 \\
\hline Age <60 years old (36) & 366.73 (179.3) & $313.46(113.2)$ & 0.0596 & & & \\
\hline Age $\geq 60$ years old $(51)$ & $453.49(219.3)$ & $387.2(153.68)$ & $0.0311^{\mathrm{a}}$ & 1.083 & $0.435-2.696$ & 0.8646 \\
\hline HBeAg positive (13) & 308.77 (119.1) & 299.23 (141.1) & $0.005^{\mathrm{b}}$ & 0.903 & $0.266-3.059$ & 0.8695 \\
\hline HBeAg negative (74) & $438.84(214.3)$ & $366.99(141)$ & 0.3463 & & & \\
\hline HBcrAg positive (45) & $412.3(215.7)$ & $327.5(129.3)$ & $0.0012^{\mathrm{b}}$ & 1.062 & $0.361-2.456$ & 0.9014 \\
\hline HBcrAg negative (42) & $431.3(210.2)$ & $370.3(128.7)$ & 0.18 & & & \\
\hline HBV-DNA positive (41) & $406.97(208.53)$ & $369.1(147.86)$ & 0.9547 & & & \\
\hline HBV-DNA negative (46) & $427.4(207.77)$ & $346.1(138.3)$ & $0.0015^{\mathrm{b}}$ & 1.232 & $0.5-3.039$ & 0.6504 \\
\hline Bone disease negative (33) & $356.57(115)$ & 364.5 (145.9) & 0.9093 & & & \\
\hline Bone disease positive (54) & $450.6(237.2)$ & $351.58(141.2)$ & $0.0007^{\mathrm{c}}$ & 2.885 & $1.044-7.972$ & $0.0411^{\mathrm{a}}$ \\
\hline Renal alteration negative (53) & $399.8(161.63)$ & $346.4(137.69)$ & $0.0043^{\mathrm{b}}$ & & & \\
\hline Renal alteration positive (34) & $446(264.1)$ & $372(150)$ & 0.2989 & 0.563 & $0.219-1.445$ & 0.2322 \\
\hline Naïve TAF (32) & $394.66(198)$ & $375.83(142.8)$ & 0.8382 & & & \\
\hline Switch ETV to TAF (55) & $430.8(212.8)$ & $346.3(142.3)$ & $0.0004^{\mathrm{c}}$ & 2.222 & $0.828-5.964$ & 0.1129 \\
\hline Treatment (67) & $403(177.2)$ & 339.88 (1249) & $0.002^{\mathrm{b}}$ & & & \\
\hline Prevention (20) & $472.24(293.28)$ & $413.37(185.2)$ & 0.4347 & 0.755 & $0.248-2.304$ & 0.6218 \\
\hline Albumin $\geq 4$ g/dl (65) & $407.42(211.7)$ & $347.75(139.6)$ & $0.0079^{\mathrm{b}}$ & & & \\
\hline Albumin $<4 \mathrm{~g} / \mathrm{dl}(22)$ & $453.1(191.56)$ & $386.4(8,151.19)$ & 0.2775 & 1.036 & $0.348-3.085$ & 0.9493 \\
\hline Platelet $\geq 15 \times 10^{4} / \mu 1$ over $(62)$ & 405.7 (193) & $352.14(146)$ & $0.0123^{\mathrm{a}}$ & & & \\
\hline Platelet $<15 \times 10^{4} / \mu 1(25)$ & $451.38(244.2)$ & $366.8(135.59)$ & 0.1218 & 0.66 & $0.232-1.878$ & 0.4360 \\
\hline $\mathrm{BMI} \geq 25(25)$ & $380(185)$ & $359.5(132.8)$ & 0.8314 & & & \\
\hline $\mathrm{BMI}<25(62)$ & $432.9(215)$ & $355.24(147.2)$ & $0.001^{\mathrm{b}}$ & 1.843 & $0.656-5.178$ & 0.2458 \\
\hline CBMM High (57) & 387 (189.9) & $344.4(134.14)$ & 0.0387 & & & \\
\hline CBMM Low (30) & $477.9(229.1)$ & $382.1(157.78)$ & 0.0573 & 1.117 & $0.431-2.899$ & 0.8193 \\
\hline
\end{tabular}

${ }^{\mathrm{a} P} \leq 0.05,{ }^{\mathrm{b}} \mathrm{P} \leq 0.01,{ }^{\mathrm{c}} \mathrm{P} \leq 0.001 .{ }^{\mathrm{d}} \mathrm{D}$ ata are presented as the mean \pm standard deviation. TRACP-5b was compared between the two groups at the start and after 1 year. The MSC of TRACP-5b was $12.4 \%$. The group that contributed to MSCs (32 cases) was analyzed by logistical analysis. The bone disease-positive group was defined as follows: Chronic steroid use or use of other medications that worsen bone density and/or history of fragility fracture and/or osteoporosis. Renal alteration was defined as follows: eGFR $<\mathrm{ml} / \mathrm{min} / 1.73 \mathrm{~m}^{2}$ and/or moderate dipstick proteinuria and/or low $\mathrm{P}(<2.5 \mathrm{mg} / \mathrm{dl})$ and/or hemodialysis. The treatment group was treated with TAF for chronic HBV infection. The prevention group was treated with TAF for asymptomatic HBV using immunosuppressants and/or anticancer drugs. The CBMM High group was defined as follows: $>27.903$ in women and $>39.731$ in men.

disease (6). HOD is based on cirrhosis and is caused by insufficient liver-related factors, vitamin $\mathrm{K}$, vitamin $\mathrm{D}$, parathyroid hormone (PTH) and fibroblast growth factor (FGF) 23 (5-7). However, in the present study, low albumin and low platelet counts were not contributing factors for the MSC of TRACP-5b. Previous population-based studies have described the relationship between HBV infection and osteoporosis $(8,9)$. It is speculated that HOD appears in pre-cirrhosis related to HBV.

TRACP-5b levels are reflected in osteoclast function, number and volume $(6,26)$, and is a bone turnover marker and predictor of fracture-independent BMD $(27,28)$. High serum $P$ was related to changes in TRACP-5b levels, and a decrease in
P for 1 year was positively related to a decrease in TRACP-5b levels. More osteoblasts were normalized by TAF, and bone reabsorption was recovered. As a result, $\mathrm{P}$ was resorbed to the bone, and serum $\mathrm{P}$ decreased (6). The results showed that TAF was effective for the amelioration of osteoclasts. Since changes in TRACP-5b are related to fracture $(11,27,28)$, BMD in the lumbar and neck of the femur was not improved by TAF; thus whether TAF could prevent fractures will be the focus of future studies.

BMD in the neck of the femur decreased during the observation period. A previous study described mean hip BMD at 1 year after TAF treatment was lower than that at the start of treatment, but less than 1 year after TDF treatment (12-14). 
A

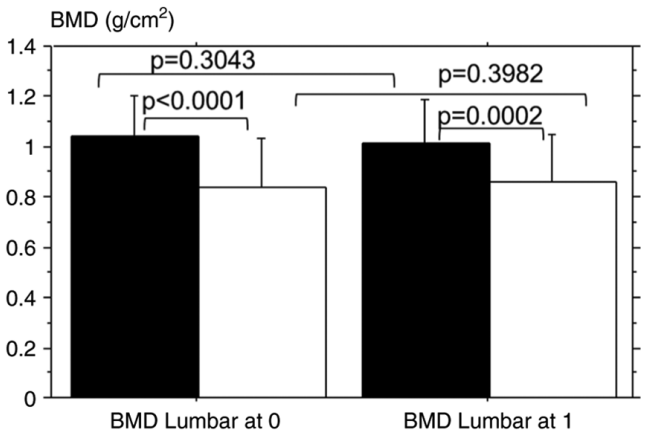

C

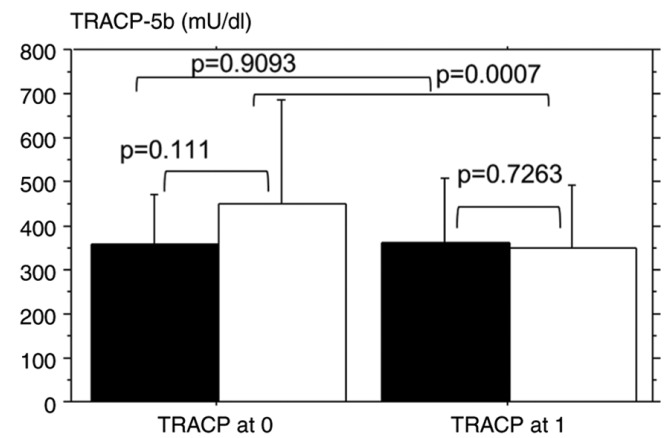

E

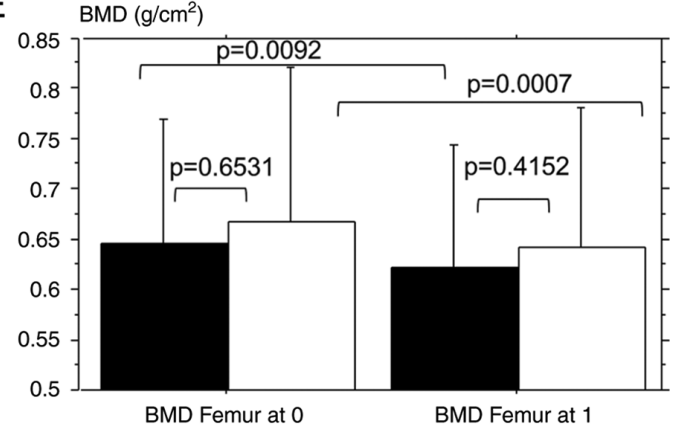

G

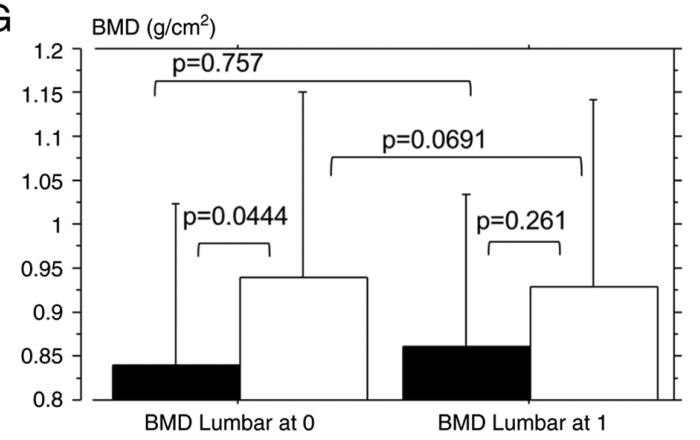

$\mathrm{B}$

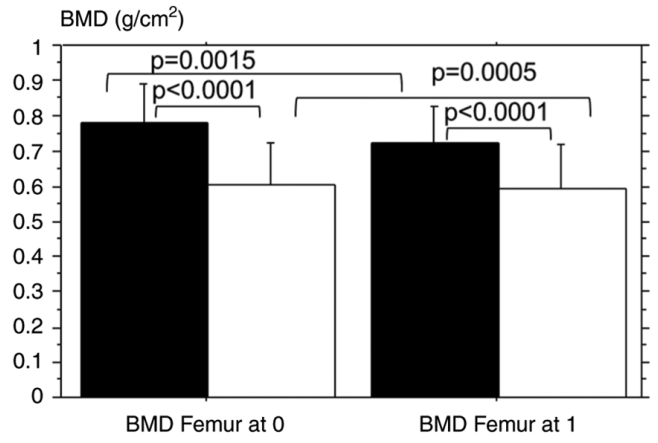

D

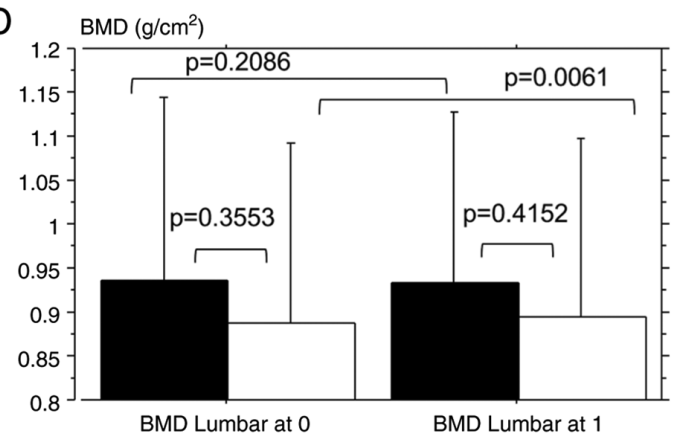

$\mathrm{F}$

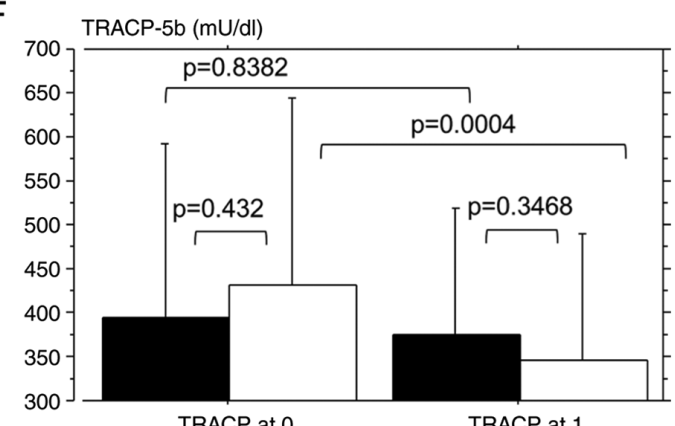

$\mathrm{H} \quad B M D\left(\mathrm{~g} / \mathrm{cm}^{2}\right)$

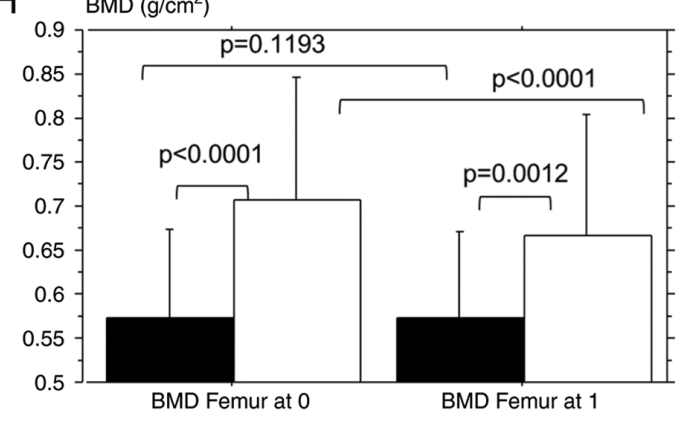

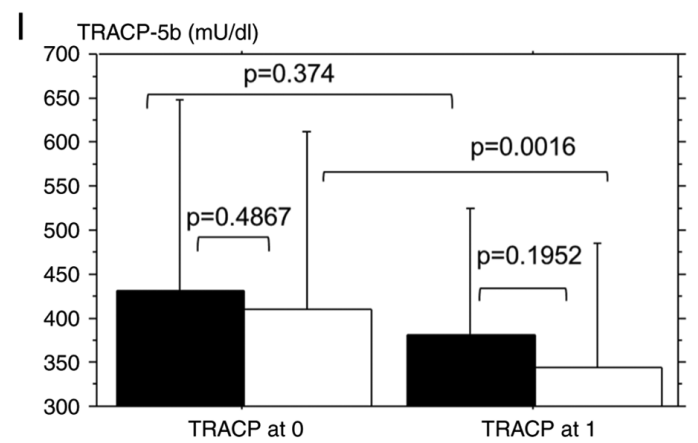

Figure 1. Change in lumbar BMD, neck of femur BMD and TRACP-5b. Differences in BMD in the lumbar and neck of the femur and TRACP-5b levels between the start of TAF (0) and 1 year after (1). (A) Lumbar BMD, (B) neck of femur BMD and (C) TRACP-5b levels were compared between bone disease-positive (white bar) and negative (black bar) conditions. (D) Lumbar BMD, (E) neck of femur BMD and (F) TRACP-5b levels were compared between naïve (black bars) and patients who switched (white bars). (G) Lumbar BMD, (H) neck of femur BMD and (I) TRACP-5b levels were compared between females (black bars) and males (white bars). In each graph, the x-axis at the start of tenofovir alafenamide administration (0) and after 1 year (1). BMD, bone mineral density; TRACP-5b, tartrate-resistant acid phosphatase isoform $5 b$. 
Table III. Rate of change in TRACP-5b levels and clinical factors.

\begin{tabular}{|c|c|c|c|c|c|c|c|c|}
\hline \multirow[b]{2}{*}{ Factor } & \multicolumn{4}{|c|}{$\begin{array}{l}\text { Factors at start and TRACP-5b } \\
\text { rate of change }\end{array}$} & \multicolumn{4}{|c|}{$\begin{array}{c}\text { Change in factor and TRACP-5b } \\
\text { change rate }\end{array}$} \\
\hline & $\mathrm{R}$ & P-value & $\beta$ & P-value & $\mathrm{R}$ & P-value & $\beta$ & P-value \\
\hline Age & -0.007 & 0.9547 & & & & & & \\
\hline Body weight & -0.05 & 0.6609 & & & -0.148 & 0.1961 & & \\
\hline Body mass index & -0.132 & 0.2481 & & & & & & \\
\hline $\mathrm{HBsAg}$ & -0.004 & 0.9711 & & & 0.014 & 0.9022 & & \\
\hline HBcrAg & 0.09 & 0.4589 & & & 0.138 & 0.2679 & & \\
\hline $\mathrm{HBeAg}$ & -0.129 & 0.2581 & & & 0.094 & 0.4359 & & \\
\hline HBV-DNA & -0.081 & 0.4813 & & & -0.038 & 0.7431 & & \\
\hline AST & 0.064 & 0.5755 & & & 0.067 & 0.5561 & & \\
\hline ALT & 0.067 & 0.5567 & & & 0.079 & 0.4925 & & \\
\hline Platelet & 0.06 & 0.5982 & & & -0.044 & 0.7019 & & \\
\hline Albumin & 0.02 & 0.8607 & & & -0.001 & 0.9905 & & \\
\hline Total bilirubin & 0.152 & 0.1803 & & & 0.158 & 0.1645 & & \\
\hline M2BPGi & 0.186 & 0.1384 & & & 0.14 & 0.2837 & & \\
\hline $\mathrm{Cr}$ & -0.178 & 0.1168 & & & -0.022 & 0.848 & & \\
\hline Cr-eGFR & 0.221 & $0.0498^{\mathrm{a}}$ & 0.267 & $0.003^{\mathrm{b}}$ & 0.025 & 0.8288 & & \\
\hline Cys C & -0.145 & 0.2042 & & & 0.006 & 0.9618 & & \\
\hline Cys C-eGFR & 0.122 & 0.2868 & & & 0.004 & 0.9743 & & \\
\hline Sarcopenia index & -0.035 & 0.7608 & & & -0.037 & 0.7626 & & \\
\hline $\mathrm{Ca}$ & 0.069 & 0.552 & & & 0.191 & 0.1026 & & \\
\hline $\mathrm{P}$ & 0.254 & $0.0244^{\mathrm{a}}$ & 0.097 & 0.3656 & 0.312 & $0.0055^{\mathrm{b}}$ & 0.312 & $0.0057^{\mathrm{b}}$ \\
\hline Urine protein/Cr & -0.125 & 0.3111 & & & 0.057 & 0.6601 & & \\
\hline Urine b2MG/Cr & 0.167 & 0.1906 & & & -0.081 & 0.5436 & & \\
\hline Lumbar BMD & -0.205 & 0.0772 & & & -0.184 & 0.1304 & & \\
\hline Lumbar t-score & -0.213 & 0.066 & & & & & & \\
\hline Lumbar young adult mean & -0.208 & 0.0737 & & & & & & \\
\hline Neck of Femur BMD & -0.127 & 0.279 & & & 0.036 & 0.7697 & & \\
\hline Neck of Femur t-score & -0.15 & 0.2003 & & & & & & \\
\hline Neck of Femur young adult mean & -0.145 & 0.2163 & & & & & & \\
\hline TRACP-5b & 0.532 & $<0.0001^{\mathrm{c}}$ & 0.533 & $0.0003^{\mathrm{c}}$ & & & & \\
\hline P1NP & 0.393 & 0.0008 & -0.005 & 0.9702 & & & & \\
\hline$\alpha$-fetoprotein & 0.097 & 0.4062 & & & 0.043 & 0.7195 & & \\
\hline PIVKA-II & -0.081 & 0.4898 & & & 0.073 & 0.5418 & & \\
\hline
\end{tabular}

${ }^{\mathrm{a}} \mathrm{P} \leq 0.05,{ }^{\mathrm{b}} \mathrm{P} \leq 0.01,{ }^{\mathrm{c}} \mathrm{P} \leq 0.001$. The relationship between factors and changes in TRACP-5b was evaluated using correlation and multiple regression models. $\mathrm{R}$ is the correlation coefficient. $\beta$ is the standardized partial regression coefficient. Only factors with a significant $\mathrm{R}$ value were analyzed by multi-regression analysis.

There was no control after 1 year; however, BMD in the lumbar spine and TRACP-5b did not worsen after 1 year. There were 18 cases of increased BMD in the femur, less than the number of cases of increased BMD in the lumbar (44 cases) and MSC (32 cases) groups. Females exhibited increased BMD in the femoral neck, and TRACP-5b did not decrease after 1 year. Differences between the femur and lumbar vertebrae in patients with $\mathrm{CHB}$ treated with TAF will continue to be observed in the future.

Increased $\mathrm{Cr}$ and decreased $\mathrm{Cr}$-eGFR were observed after 1 year of TAF treatment. However, CysC and CysC eGFR were not altered significantly during the treatment period.
The SI indicates muscle volume and prognosis in patients in the intensive care unit (23). SI elevation reflects an increase in $\mathrm{Cr}$, whilst $\mathrm{Cys} \mathrm{C}$ remains unchanged, and this is indicative of muscle volume gain. Changes in muscle mass should also be evaluated in future studies. Urine protein/creatinine ratio was elevated after 1 year, but the $\beta 2 \mathrm{MG} /$ creatinine ratio did not differ during the observational period. Previous reports did not identify the adverse effects of TAF on the kidney (14-17). In contrast to previous reports, the prevention group in the present study (20 cases) were treated with anticancer agents and/or immunosuppressants at the start of TAF administration, and this was continued after 1 year. It is hypothesized that there 
Table IV. Change of BMD in the lumbar region and factors contributing to the increased BMD in the lumbar region.

\begin{tabular}{|c|c|c|c|c|c|c|}
\hline \multirow[b]{3}{*}{ Group (n) } & \multirow{2}{*}{\multicolumn{3}{|c|}{ Comparison with BMD in Lumbar }} & \multicolumn{3}{|c|}{$\begin{array}{l}\text { Factors contributing to the increase } \\
\text { in BMD in the lumbar region }\end{array}$} \\
\hline & & & & \multirow{2}{*}{$\begin{array}{l}\text { Odds } \\
\text { ratio }\end{array}$} & \multirow{2}{*}{$\begin{array}{l}95 \% \text { confidence } \\
\text { interval }\end{array}$} & \multirow[b]{2}{*}{ P-value } \\
\hline & At start & After 1 year & P-value & & & \\
\hline Female (29) & $0.839(0.184)$ & $0.861(0.171)$ & 0.757 & & & \\
\hline Male (58) & $0.94(0.184)$ & $0.93(0.211)$ & 0.0691 & & & \\
\hline Age <60 years old (36) & $0.906(0.155)$ & $0.908(0.146)$ & 0.896 & & & \\
\hline Age $\geq 60$ years old $(51)$ & $0.906(0.239)$ & $0.906(0.234)$ & 0.1428 & & & \\
\hline HBeAg positive (13) & $0.858(0.157)$ & $0.888(0.143)$ & 0.2791 & & & \\
\hline HBeAg negative (74) & $0.913(0.213)$ & $0.91(0.208)$ & 0.4752 & & & \\
\hline HBcrAg positive (45) & $0.925(0.181)$ & $0.936(0.177)$ & 0.7915 & & & \\
\hline HBcrAg negative (42) & $0.875(0.243)$ & $0.866(0.229)$ & 0.0926 & & & \\
\hline HBV-DNA positive (41) & $0.923(0.202)$ & $0.942(0.169)$ & 0.7531 & & & \\
\hline HBV-DNA negative (46) & $0.89(0.211)$ & $0.881(0.219)$ & 0.147 & & & \\
\hline Bone disease negative (33) & $1.046(0.155)$ & $1.013(0.173)$ & 0.3043 & & & \\
\hline Bone disease positive (54) & $0.841(0.195)$ & $0.857(0.193)$ & 0.3982 & & & \\
\hline Renal alteration negative (53) & $0.888(0.205)$ & $0.876(0.208)$ & 0.8126 & & & \\
\hline Renal alteration positive (34) & $0.935(0.208)$ & $0.959(0.178)$ & 0.0875 & & & \\
\hline Naïve TAF (32) & $0.934(0.21)$ & $0.933(0.193)$ & 0.2086 & & & \\
\hline Switch ETV to TAF (55) & $0.888(0.204)$ & $0.894(0.204)$ & $0.0061^{\mathrm{a}}$ & 3.923 & $1.409-10.925$ & $0.0089^{\mathrm{a}}$ \\
\hline Treatment (67) & $0.898(0.2)$ & $0.891(0.194)$ & 0.1459 & & & \\
\hline Prevention (20) & $0.936(0.235)$ & $0.972(0.251)$ & 0.9999 & & & \\
\hline Albumin $\geq 4$ g/dl (65) & $0.898(0.208)$ & $0.889(0.199)$ & 0.3172 & & & \\
\hline Albumin $<4 \mathrm{~g} / \mathrm{dl}(22)$ & $0.936(0.202)$ & $0.913(0.21)$ & 0.3061 & & & \\
\hline Platelet count $\geq 15 \times 10^{4} / \mu 1(62)$ & $0.902(0.216)$ & $0.913(0.21)$ & 0.089 & & & \\
\hline Platelet count $<15 \times 10^{4} / \mu 1(25)$ & $0.916(0.181)$ & $0.89(0.173)$ & 0.6231 & & & \\
\hline Body mass index $\geq 25$ (25) & $1.051(0.214)$ & $1.049(0.203)$ & 0.8562 & & & \\
\hline Body mass index <25 (62) & $0.846(0.172)$ & $0.852(0.171)$ & 0.1029 & & & \\
\hline CBMM High (57) & $0.955(0.213)$ & $0.953(0.211)$ & 0.1972 & & & \\
\hline CBMM Low (30) & $0.81(0.155)$ & $0.816(0.139)$ & 0.511 & & & \\
\hline
\end{tabular}

${ }^{\mathrm{a}} \mathrm{P}<0.01$. BMD in the lumbar spine was compared at the start and after 1 year. Data are presented as the mean \pm standard deviation. Increased BMD was defined as: BMD at the start < BMD after 1 year. An increase in BMD was observed in 44 patients. The contributing factors were analyzed using logistic regression analysis.

is a relationship between concomitant drug use with TAF and proteinuria.

Switching ETV to TAF was a contributing factor in the increased BMD in the lumbar spine. The Switch group showed decreased TRACP-5b levels. TAF treatment resulted in less BMD loss than TDF treatment (12-14), but BMD gain was not observed. In the switch from ETV to TAF, BMD was not changed after 48 weeks in a previous report (17), and there was no significant increase in the incidence of osteoporosis/osteopenia in patients with $\mathrm{CHB}$ treated with TDF or ETV compared to those without treatment (29). It may seem that reduced BMD may be partly due to underlying chronic liver disease, and several patients with $\mathrm{CHB}$ may already have pre-existing low BMD prior to commencing antiviral therapy $(8,9,30)$. Long-term observations are required to explore the anti-HBV effects of NAs and BMD.
The present study has some limitations. This was a single-center, small retrospective study, including prevention and a 1 year observational analysis. Thus, it was not possible to evaluate HOD-related bone related hormones, such as FGF23, $\mathrm{PTH}$, vitamin D and vitamin $\mathrm{K}$. The protective effects of TAF on renal function has been now widely established $(3,12)$. However, it may be possible to ascertain additional useful information regarding the relationship between $\mathrm{HBV}$ infection and bone metabolism.

In conclusion, patients with HBV infection complicated by bone disease exhibited decreased TRACP-5b levels after treatment with TAF. Switching ETV to TAF increased BMD in the lumbar spine and decreased the TRAC-5b levels. TAF is acceptable for improving/maintaining bone metabolism in patients with HBV infection, and TRACP-5b was shown to be a useful bone metabolic marker, especially when attempting to prevent fractures in patients with HBV. 
Table V. Change of BMD in the neck of femur and factors contributing to the increased BMD in the neck of femur.

\begin{tabular}{|c|c|c|c|c|c|c|}
\hline \multirow[b]{3}{*}{ Group (n) } & \multirow{2}{*}{\multicolumn{3}{|c|}{ Comparison with BMD in the neck of femur }} & \multicolumn{3}{|c|}{$\begin{array}{l}\text { Factors contributing to the in BMD } \\
\text { in the neck of femur }\end{array}$} \\
\hline & & & & \multirow{2}{*}{$\begin{array}{l}\text { Odds } \\
\text { ratio }\end{array}$} & \multirow{2}{*}{$\begin{array}{l}95 \% \text { confidence } \\
\text { interval }\end{array}$} & \multirow[b]{2}{*}{ P-value } \\
\hline & At $\operatorname{start}^{\mathrm{e}}$ & After 1 year $^{\mathrm{e}}$ & P-value & & & \\
\hline Female (29) & $0.572(0.101)$ & $0.574(0.098)$ & 0.1193 & & & \\
\hline Male (58) & $0.705(0.14)$ & $0.667(0.137)$ & $<0.0001^{\mathrm{d}}$ & 0.308 & $0.102-0.928$ & $0.0364^{\mathrm{a}}$ \\
\hline Age <60 years old (36) & $0.702(0.128)$ & $0.671(0.11)$ & $0.0011^{\mathrm{b}}$ & & & \\
\hline Age $\geq 60$ years old $(51)$ & $0.629(0.146)$ & $0.61(0.142)$ & $0.0008^{\mathrm{c}}$ & & & \\
\hline HBeAg positive (13) & $0.603(0.079)$ & $0.594(0.078)$ & $<0.0001^{\mathrm{d}}$ & & & \\
\hline HBeAg negative (74) & $0.669(0.148)$ & $0.642(0.138)$ & $0.0467^{\mathrm{a}}$ & & & \\
\hline HBcrAg positive (45) & $0.693(0.136)$ & $0.672(0.117)$ & $0.0003^{\mathrm{c}}$ & & & \\
\hline HBcrAg negative (42) & $0.622(0.156)$ & $0.595(0.152)$ & $0.0104^{\mathrm{a}}$ & & & \\
\hline HBV-DNA positive (41) & $0.644(0.121)$ & $0.637(0.113)$ & $0.0402^{\mathrm{a}}$ & & & \\
\hline HBV-DNA negative (46) & $0.674(0.159)$ & $0.635(0.147)$ & $<0.0001^{\mathrm{d}}$ & & & \\
\hline Bone disease negative (33) & $0.78(0.108)$ & $0.726(0.102)$ & $0.0015^{\mathrm{b}}$ & & & \\
\hline Bone disease positive (54) & $0.604(0.12)$ & $0.594(0.124)$ & $0.0005^{\mathrm{c}}$ & & & \\
\hline Renal alteration negative (53) & $0.663(0.1439$ & $0.634(0.134)$ & $0.0001^{\mathrm{d}}$ & & & \\
\hline Renal alteration positive (34) & $0.655(0.142)$ & $0.638(0.131)$ & $0.0092^{c}$ & & & \\
\hline Naïve TAF (32) & $0.647(0.124)$ & $0.623(0.122)$ & $0.0007^{\mathrm{c}}$ & & & \\
\hline Switch ETV to TAF (55) & $0.668(0.153)$ & $0.643(0.138)$ & $0.0012^{\mathrm{c}}$ & & & \\
\hline Treatment (67) & $0.665(0.134)$ & $0.643(0.118)$ & $<0.0001^{\mathrm{d}}$ & & & \\
\hline Prevention (20) & $0.641(0.175)$ & $0.608(0.181)$ & 0.0621 & 0.782 & $0.192-3.188$ & 0.7314 \\
\hline Albumin $\geq 4$ g/dl (65) & $0.651(0.149)$ & $0.635(0.141)$ & $<0.0001^{\mathrm{d}}$ & & & \\
\hline Albumin <4 g/dl (22) & $0.685(0.118)$ & $0.639(0.106)$ & 0.2238 & 2.582 & $0.703-9.493$ & 0.1531 \\
\hline Platelet count $\geq 15 \times 10^{4} / \mu 1(62)$ & $0.729(0.141)$ & $0.714(0.119$ & $<0.0001^{\mathrm{d}}$ & & & \\
\hline Platelet $<15 \times 10^{4} / \mu 1(25)$ & $0.632(0.134)$ & $0.606(0.125)$ & $0.0457^{\mathrm{a}}$ & & & \\
\hline Body mass index $\geq 25$ (25) & $0.729(0.141)$ & $0.714(0.119)$ & 0.1043 & & & \\
\hline Body mass index <25 (62) & $0.632(0.134)$ & $0.606(0.125)$ & $<0.0001^{\mathrm{d}}$ & 0.357 & $0.115-1.105$ & 0.074 \\
\hline CBMM High (57) & $0.7(0.129)$ & $0.678(0.125)$ & $<0.0001^{\mathrm{d}}$ & & & \\
\hline CBMM Low (30) & $0.583(0.136)$ & $0.551(0.105)$ & $0.0114^{\mathrm{a}}$ & & & \\
\hline
\end{tabular}

${ }^{\mathrm{a}} \mathrm{P} \leq 0.05,{ }^{\mathrm{b}} \mathrm{P} \leq 0.01,{ }^{\mathrm{c}} \mathrm{P} \leq 0.001,{ }^{\mathrm{d}} \mathrm{P} \leq 0.0001$. BMD in the neck of femur was compared at the start and after 1 year. ${ }^{\mathrm{e}}$ Data are presented as the mean \pm standard deviation. Increased BMD was defined as: BMD at the start < BMD after 1 year. An increase in BMD was observed in 18 patients. The contributing factors for increased BMD after 1 year were analyzed using logistic regression analysis.

\section{Acknowledgements}

Not applicable.

\section{Funding}

No funding was received.

\section{Availability of data and materials}

The datasets used and/or analyzed during the present study are available from the corresponding author on reasonable request.

\section{Authors' contributions}

TO and TIc wrote the manuscript, analyzed the data and designed the study. HM, SM, YM, MY, SY, MK, TH, HY, TIk, OM, YK, YN, NT and KN collected the data. All authors have read and approved the final manuscript. KN and NT confirm the authenticity of all the raw. data.

\section{Ethics approval and consent to participate}

The present study was approved by the Human Research Ethics Committee of the Nagasaki Harbor Medical Center (approval no. H30-031). Informed consent was obtained from each patient included in the study, and the patients were guaranteed the right to leave the study if they desired.

\section{Patient consent for publication}

Not applicable.

\section{Competing interests}

The authors declare that they have no competing interests. 


\section{References}

1. Papatheodoridis G, Buti M, Cornberg M, Janssen H, Mutimer D, Pol S and Raimondo G: EASL clinical practice guidelines: Management of chronic hepatitis B virus infection. J Hepatol 57: 167-185, 2012.

2. Raffetti E, Fattovich G and Donato F: Incidence of hepatocellular carcinoma in untreated subjects with chronic hepatitis B: A systematic review and meta-analysis. Liver Int 36: 1239-1251, 2016.

3. Lampertico P, Agarwal K, Berg T, Buti M, Janssen HLA, Papatheodoridis G, Zoulim F and Tacke F: EASL 2017 clinical practice guidelines on the management of hepatitis B virus infection. J Hepatol 67: 370-398, 2017.

4. Si J, Yu C, Guo Y, Bian Z, Qin C, Yang L, Chen Y, Yin L, Li H, Lan J, et al: Chronic hepatitis B virus infection and risk of chronic kidney disease: A population-based prospective cohort study of 0.5 million Chinese adults. BMC Med 16: 93, 2018.

5. Rouillard S and Lane NE: Hepatic osteodystrophy. Hepatology 33: 301-307, 2001.

6. Ehnert S, Aspera-Werz RH, Ruoß M, Dooley S, Hengstler JG, Nadalin S, Relja B, Badke A and Nussler AK: Hepatic osteodystrophy-molecular mechanisms proposed to favor its development. Int J Mol Sci 20: 2555, 2019.

7. Leslie WD, Bernstein CN, Leboff MS; American Gastroenterological Association Clinical Practice Commitee AGA technical review on osteoporosis in hepatic disorders. Gastroenterology 125: 941-966, 2003.

8. Chen CH, Lin CL and Kao CH: Association between chronic hepatitis B virus infection and risk of osteoporosis: A nationwide population-based study. Medicine (Baltimore) 94: e2276, 2015.

9. Baeg MK, Yoon SK, Ko SH, Han KD, Choi HJ, Bae SH, Choi JY and Choi MG: Males seropositive for hepatitis B surface antigen are at risk of lower bone mineral density: The 2008-2010 Korea national health and nutrition examination surveys. Hepatol Int 10: 470-477, 2016.

10. Shimizu T, Arita K, Murota E, Hiratsuka S, Fujita R, Ishizu H, Asano T, Takahashi D, Takahata M and Iwasaki N: Effects after starting or switching from bisphosphonate to romosozumab or denosumab in Japanese postmenopausal patients. J Bone Miner Metab 39: 868-875, 2021

11. Miller PD, Hochberg MC, Wehren LE, Ross PD and Wasnich RD: How useful are measures of BMD and bone turnover? Curr Med Res Opin 21: 545-554, 2005.

12. Agarwal K, Brunetto M, Seto WK, Lim YS, Fung S, Marcellin P, Ahn SH, Izumi N, Chuang WL, Bae H, et al: 96 weeks treatment of tenofovir alafenamide vs tenofovir disoproxil fumarate for hepatitis B virus infection. J Hepatol 68: 672-681, 2018.

13. Seto WK, Asahina Y, Brown TT, Peng CY, Stanciu C, Abdurakhmanov D, Tabak F, Nguyen TT, Chuang WL, Inokuma T, et al: Improved bone safety of tenofovir alafenamide compared to tenofovir disoproxil fumarate over 2 years in patients with chronic HBV infection. Clin Gastroenterol Hepatol, Jun 20, 2018 (Online ahead of print).

14. Chan HL, Fung S, Seto WK, Chuang WL, Chen CY, Kim HJ, Hui AJ, Janssen HL, Chowdhury A, Tsang TY, et al: Tenofovir alafenamide versus tenofovir disoproxil fumarate for the treatment of $\mathrm{HBeAg}$-positive chronic hepatitis B virus infection: A randomised, double-blind, phase 3, non-inferiority trial. Lancet Gastroenterol Hepatol 1: 185-195, 2016.

15. Ogawa E, Nomura H, Nakamuta M, Furusyo N, Koyanagi T, Dohmen K, Ooho A, Satoh T, Kawano A, Kajiwara E, et al: Tenofovir alafenamide after switching from entecavir or nucleos(t)ide combination therapy for patients with chronic hepatitis B. Liver Int 40: 1578-1589, 2020.
16. Notsumata K, Nomura Y, Tanaka A, Ueda T, Sanada T, Watanabe $\mathrm{H}$ and Toya D: Early changes in tubular dysfunction markers and phosphorus metabolism regulators as a result of switching from entecavir to tenofovir alafenamide fumarate nucleoside analog therapy for chronic hepatitis B patients. Hepatol Res 50: 402-404, 2020.

17. Hagiwara S, Nishida N, Ida H, Ueshima K, Minami Y, Takita M, Komeda Y and Kudo M: Switching from entecavir to tenofovir alafenamide versus maintaining entecavir for chronic hepatitis B J Med Virol 91: 18040-1810, 2019.

18. Uchida Y, Nakao M, Tsuji S, Uemura H, Kouyama JI, Naiki K, Motoya D, Sugawara K, Nakayama N, Imai Y, et al: Significance of switching of the nucleos(t)ide analog used to treat Japanese patients with chronic hepatitis B virus infection from entecavir to tenofovir alafenamide fumarate. J Med Virol 92: 329-338, 2020

19. Tamaki N, Kurosaki M, Nakanishi H, Itakura J, Inada K, Kirino S, Kirino S, Yamashita K, Osawa L, Sekiguchi S, et al: Comparison of medication adherence and satisfaction between entecavir and tenofovir alafenamide therapy in chronic hepatitis B. J Med Virol 92: 1355-1358, 2020.

20. Shephard DA: The 1975 declaration of Helsinki and consent. Can Med Assoc J 115: 1191-1192, 1976.

21. Assessment of fracture risk and its application to screening for postmenopausal osteoporosis. Report of a WHO study group. World Health Organ Tech Rep Ser 843: 1-129, 1994.

22. Matsuo S, Imai E, Horio M, Yasuda Y, Tomita K, Nitta K, Yamagata K, Tomino Y, Yokoyama $\mathrm{H}$ and Hishida A; Collaborators developing the Japanese equation for estimated GFR: Revised equations for estimated GFR from serum creatinine in Japan. Am J Kidney Dis 53: 982-992, 2009.

23. Kashani KB, Frazee EN, Kukrálová L, Sarvottam K, Herasevich V, Young PM, Kashyap R and Lieske JC: Evaluating muscle mass by using markers of kidney function: Development of the sarcopenia index. Crit Care Med 45: e23-e29, 2017.

24. Kim SW, Jung HW, Kim CH, Kim K, Chin HJ and Lee H: A new equation to estimate muscle mass from creatinine and cystatin $\mathrm{C}$. PLoS One 11: e0148495, 2016.

25. Spirlandeli AL, Dick-de-paula I, Zamarioli A, Jorgetti V, Ramalho LNZ, Nogueira-Barbosa MH, Volpon JB, Jordão AA, Cunha FQ, Fukada SY and de Paula FJA: Hepatic osteodystrophy: The mechanism of bone loss in hepatocellular disease and the effects of pamidronate treatment. Clinics (Sao Paulo) 72: 231-237, 2017.

26. Lv Y, Wang G, Xu W, Tao P, Lv X and Wang Y: Tartrate-resistant acid phosphatase $5 \mathrm{~b}$ is a marker of osteoclast number and volume in RAW 264.7 cells treated with receptor-activated nuclear $\kappa \mathrm{B}$ ligand. Exp Ther Med 9: 143-146, 2015.

27. Ivaska KK, Gerdhem P, Väänänen HK, Akesson K and Obrant KJ: Bone turnover markers and prediction of fracture: A prospective follow-up study of 1040 elderly women for a mean of 9 years. J Bone Miner Res 25: 393-403, 2010.

28. Kasai H, Mori Y, Ose A, Shiraki M and Tanigawara Y: Prediction of fracture risk from early-stage bone markers in patients with osteoporosis treated with once-yearly administered zoledronic acid. J Clin Pharmacol 61: 606-613, 2021.

29. Wei MT, Le AK, Chang MS, Hsu H, Nguyen P, Zhang JQ, Wong C, Wong C, Cheung R and Nguyen MH: Antiviral therapy and the development of osteopenia/osteoporosis among Asians with chronic hepatitis B. J Med Virol 91: 1288-1294, 2019.

30. Fung J, Seto W, Lai C and Yuen M: Extrahepatic effects of nucleoside and nucleotide analogues in chronic hepatitis B treatment J Gastroenterol Hepatol 29: 428-434, 2014.

This work is licensed under a Creative Commons Attribution-NonCommercial-NoDerivatives 4.0 International (CC BY-NC-ND 4.0) License. 